\title{
PENGARUH SISTEM OLAH TANAH DAN PEMBERIAN MULSA ORGANIK TERHADAP ALIRAN PERMUKAAN DAN EROSI PADA PERTANAMAN KACANG HIJAU (Vigna radiata) MUSIM TANAM KE EMPAT DI LABORATORIUM LAPANG TERPADU FAKULTAS PERTANIAN UNIVERSITAS LAMPUNG
}

\author{
THE EFFECT OF TILLAGE SYSTEM AND ORGANIC MULCH AGAINST \\ SURFACE RUNOFF AND EROSION IN THE FOURTH PLANTING SEASON \\ OF GREEN BEAN (Vigna radiata) AT THE INTEGRATED FIELD LABORA- \\ TORY OF THE FACULTY OF AGRICULTURE \\ UNIVERSITY OF LAMPUNG
}

\author{
Ahmad Shan Kemala Jaya*, Irwan Sukri Banuwa, Hery Novpriansyah dan Muhajir Utomo \\ Program Studi Agroteknologi Fakultas Pertanian Universitas Lampung \\ JL. Prof. Dr. Soemantri Brojonegoro, No. 1 Bandar Lampung 35145 \\ *E-mail:ahmad.shan94@gmail.com
}

\begin{abstract}
Tillage can significantly affect soil susceptibility to erosion which can accelerate and increase the rate of erosion. The use of mulch can reduce erosion by reducing the impact energy of falling rain so it does not damage the structure and aggregate of the soil, reducing speed, volume and scouring of surface runoff. This study aims to determine the effect of (1) tillage systems on surface runoff and erosion in green bean plant (2) applying organic mulch to the amount of surface runoff and erosion in green bean plant (3) the interaction between the tillage system and the use of mulch on surface runoff and erosion in green bean plant. This research was conducted in March to June 2017 in the Integrated Field Laboratory of the Faculty of Agriculture, University of Lampung. The design used is factorial in the Complete Randomized Block Design (RCBD) on two treatment factors namely the tillage system and the mulch with four replications. The results showed that the tillage system did not significantly affect all observed variables. In the treatment of giving and without mulch also did not significantly affect all observed variables. The response of surface runoff and erosion in green bean plant to the tillage system does not depend on the organic mulch shown on all variables.
\end{abstract}

Keywords: Green bean, organic mulch, tillage system

\begin{abstract}
ABSTRAK
Pengolahan tanah secara signifikan dapat mempengaruhi kerentanan tanah terhadap erosi yang dapat mempercepat dan memperbesar laju erosi. Penggunaan mulsa dapat mengurangi erosi dengan cara meredam energi tumbuk butir-butir hujan yang jatuh sehingga tidak merusak struktur dan agregat tanah, mengurangi kecepatan, volume
\end{abstract}


dan gerusan aliran permukaan. Penelitian ini bertujuan untuk mengetahui pengaruh (1) sistem olah tanah terhadap aliran permukaan dan erosi pada pertanaman kacang hijau; (2) pemberian mulsa organik terhadap besarnya aliran permukaan dan erosi pada pertanaman kacang hijau; (3) interaksi antara sistem olah tanah dan penggunaan mulsa terhadap aliran permukaan dan erosi pada pertanaman kacang hijau. Penelitian ini dilakukan pada Maret sampai Juni 2017 di Laboratorium Lapang Terpadu Fakultas Pertanian Universitas Lampung. Rancangan yang digunakan yaitu faktorial dalam Rancangan Acak Kelompok Lengkap (RAKL) pada dua faktor perlakuan yaitu sistem olah tanah dan pemberian mulsa dengan empat kali ulangan. Hasil penelitian menunjukkan bahwa perlakuan pengolahan tanah tidak berpengaruh nyata pada semua variabel pengamatan. Pada perlakuan pemberian dan tanpa mulsa juga tidak berpengaruh nyata pada semua variabel pengamatan. Respon aliran permukaan dan erosi pada pertanaman kacang hijau terhadap sistem olah tanah tidak bergantung pada pemberian mulsa organic yang ditunjukkan pada semua variabel.

Kata Kunci : Kacang hijau, mulsa organik, sistem olah tanah

\section{PENDAHULUAN}

Pengolahan tanah merupakan tehnik dalam memanipulasi tanah secara mekanik. Tujuan dari olah tanah yaitu untuk menggemburkan tanah, mencampurkan serasah sisa tanaman dengan tanah dan menciptakan tempat agar pertumbuhan dan perkembangan akar dapat tumbuh dengan baik (Gill dan Vanden Berg, 1967) .

Sistem pengolahan tanah dibagi dua, yaitu pengolahan tanah konvensional dan pengolahan tanah konservasi (Gajri, dkk., 2002). Pengolahan tanah konvensional dikenal dengan istilah Olah Tanah Intensif (OTI). Pada pengolahan tanah intensif, tanah diolah beberapa kali menggunakan alat tradisional seperti cangkul ataupun menggunakan bajak singkal dengan membersihkan permukaan tanah dari gulma dan mulsa, serta lapisan olah tanah digemburkan agar perakaran tanaman berkembang dengan baik (Utomo, 2012).

Olah tanah minimum adalah teknik konservasi tanah dimana gangguan mekanis terhadap tanah diupayakan sesedikit mungkin. Dengan cara ini kerusakan struktur tanah dapat dihindari sehingga aliran permukaan dan erosi berkurang. Teknik ini juga mengurangi biaya dan tenaga kerja untuk pengolahan tanah dan mengurangi biaya untuk penyiangan. Pengolahan tanah minimum cukup efektif dalam mengendalikan erosi, dan biasa dilakukan pada tanah yang rentan terhadap erosi. Kekurangan pada olah tanah minimum yaitu pertumbuhan perakaran terbatas akibat struktur keras dan perlu dilakukan pemberian mulsa secara terus menerus (Wahyuningtyas, 2010).

Pemberian mulsa organik yang berasal dari sisa - sisa tumbuhan merupakan sumber energi yang akan meningkatkan energi yang akan meningkatkan kegiatan biologi tanah dan dalam proses perombakannya akan terbentuk senyawa organik yang berperan dalam pembentukan struktur tanah yang mantap. Sehingga kemantapan struktur tanah akan meningkat, aerasi menjadi lebih baik dan permeabilitas tanah yang tinggi terpelihara (Jacks, Brind dan Smith, 1995; Russel, 
1968; dan Kohnke, 1968 dalam Arsyad, 2010). Oleh karena itu diperlukan olah tanah konservasi dan pemberian mulsa untuk menekan besarnya aliran permukaan dan erosi.

\section{BAHAN DAN METODE}

Penelitian ini dilaksanakan pada bulan Maret sampai dengan bulan Juni tahun 2017 di Laboratorium Lapang Terpadu dan Laboratorium Ilmu Tanah, Fakultas Pertanian Universitas Lampung. Bahan-bahan yang digunakan pada penelitian ini adalah benih kacang hijau, pupuk ponska, mulsa organik, dan bahan lain yang digunakan untuk keperluan analisis di laboratorium. Alat-alat yang digunakan adalah petak erosi ukuran $4 \mathrm{~m} \times 4 \mathrm{~m}=16 \mathrm{~m}^{2}$, pengukur erosi atau sedimen (saringan dan sendok), pengukur aliran permukaan (gelas ukur), pengukur curah hujan (ombrometer), cangkul, dan alat-alat yang digunakan pada analisis laboratorium adalah (timbangan, oven, cawan alumunium. Penelitian pengukuran erosi menggunakan petak kecil (multislot deviser). Perlakuan dalam penelitian ini disusun secara faktorial dalam Rancangan Acak Kelompok Lengkap (RAKL). Perlakuan terdiri dari dua faktor, faktor pertama meliputi sistem olah tanah,(T) yaitu olah tanah minimum $\left(\mathrm{T}_{0}\right)$ dan olah tanah penuh $\left(\mathrm{T}_{1}\right)$, dan faktor kedua pemberian mulsa $\left(\mathrm{M}_{1}\right)$ dan tanpa pemberian mulsa $\left(\mathrm{M}_{0}\right)$.

Pada penelitian ini lahan dibersihkan dari gulma dan sisa tanaman yang ditanam sebelumnya yaitu tanaman jagung menggunakan sabit. Semua gulma dan sisa tanaman jagung dikumpulkan yang nantinya akan digunakan sebagai mulsa. Pada petak dengan perlakuan olah tanah intensif tanah dicangkul dan dibalik lalu gulma dan sisa tanaman dikeluarkan dari petak percobaan sehingga permukaan tanah bersih. Pada olah tanah minimum pengolahan tanah hanya diolah disekitar lubang tanam dan sisa gulma dan sisa tanaman dikembalikan di petak percobaan

Petak erosi yang digunakan pada penelitian ini berukuran $4 \mathrm{~m} \times$ 4m dengan dinding yang terbuat dari beton pada kemiringan lereng sebesar 12,5\%. Pada bagian bawah petak erosi terdapat bak berukuran 100 $\mathrm{cm} \times 50 \mathrm{~cm} \times 50 \mathrm{~cm}$ yang berfungsi untuk penampung aliran permukaan dan tanah yang tererosi. Bak tersebut memiliki 5 buah lubang yang berfungsi untuk saluran pembuangan apabila volume air yang ada pada bak erosi terlalu banyak. Lubang yang berada ditengah bak disalurkan menuju sebuah drum penampung yang berfungsi untuk mengukur besarnya jumlah aliran permukaan dan erosi. Besarnya aliran permukaan dihitung dengan cara menjumlahkan volume air yang berada di dalam bak dengan volume air yang ada di dalam drum dikalikan dengan lima. Volume air yang ada di dalam drum dikalikan lima karena terdapat lima buah saluran pembuangan. Bak dan drum tersebut kemudian ditutup dengan rapat agar tidak tercampur dengan air hujan sehingga data yang diperoleh akurat

\section{HASIL DAN PEMBAHASAN}

Perlakuan sistem olah tanah tidak berbeda nyata mempengaruhi aliran permukaan. Menurut Nurmi,dkk (2012) bahwa aliran permukaan lebih berpengaruh pada kemiringan lereng dibandingkan 
dengan kerusakan yang ditimbulkan oleh pengolahan tanah. Pengaruh kemiringan lereng lebih dominan dalam menyebabkan aliran permukaan dibandingkan dengan pengaruh sifat fisik tanah.

Perlakuan mulsa juga tidak berbeda nyata mempengaruhi aliran permukaan. Hal ini tidak sejalan dengan Suwardjo (1981) yang menyatakan bahwa perlakuan pengolahan tanah dan pemberian mulsa nyata menekan aliran permukaan. Pada penelitian Suwardjo curah hujan yang terjadi selama penelitian yaitu 1484 $\mathrm{mm} /$ musim tanam, sedangkan pada penelitian ini hanya sebesar $565 \mathrm{~mm} /$ musim tanam dan curah hujan yang menimbulkan aliran permukaan pada penelitian ini sebesar $16.26 \mathrm{~mm} /$ musim tanam. Hal ini diduga peran mulsa dalam menekan aliran permukaan tidak terlihat pengaruhnya karena curah hujan yang terjadi selama penelitian rendah.

Menurut Arsyad (2010) aliran permukaan tanah menjadi penting untuk diketahui, karena merupakan faktor yang berbanding lurus terhadap jumlah tanah yang tererosi. Semakin meningkat jumlah aliran permukaan maka jumlah tanah tererosi juga bertambah besar. Proses erosi berjalan hebat pada tanah-tanah gundul, terutama apabila vegetasi di atas tanah dihilangkan dan tanahnya diolah secara intensif. Hujan dengan curah hujan dan intensitas tinggi,

Tabel 1. Hasil pengamatan pengaruh sistem olah tanah dan aplikasi mulsa pada variabel aliran permukaan

\begin{tabular}{|c|c|c|c|c|c|c|c|}
\hline \multirow{2}{*}{ Perlakuan } & \multicolumn{4}{|c|}{ Ulangan } & \multirow[t]{2}{*}{ Jumlah } & \multirow[t]{2}{*}{ Rata-Rata } & \multirow[t]{2}{*}{ Standar Deviasi } \\
\hline & 1 & 2 & 3 & 4 & & & \\
\hline & \multicolumn{7}{|c|}{$\ldots \ldots \ldots \ldots \ldots \ldots \ldots \ldots m m / m u s i m$ tanam $\ldots \ldots \ldots \ldots \ldots \ldots$} \\
\hline $\mathrm{T}_{1} \mathrm{M}_{0}$ & 1,65 & 2,79 & 3,40 & 3,99 & 11,82 & 2,96 & 1,00 \\
\hline $\mathrm{T}_{0} \mathrm{M}_{0}$ & 4,44 & 5,16 & 2,28 & 1,54 & 13,42 & 3,35 & 1,72 \\
\hline $\mathrm{T}_{1} \mathrm{M}_{1}$ & 2,95 & 1,97 & 1,66 & 3,02 & 9,60 & 2,40 & 0,69 \\
\hline $\mathrm{T}_{0} \mathrm{M}_{1}$ & 3,12 & 3,64 & 2,89 & 2,54 & 12,19 & 3,05 & 0,46 \\
\hline Total & 12,16 & 13,55 & 10,23 & 11,09 & 35,94 & 11,76 & 3,87 \\
\hline Rata-rata & 3,04 & 3,39 & 2,56 & 2,77 & & & \\
\hline
\end{tabular}

Keterangan : $\mathrm{T}_{0}=$ Olah Tanah Minimum; $\mathrm{T}_{1}=$ Olah Tanah Intensif; $\mathrm{M}_{0}=$ Tanpa mulsa; $\mathrm{M}_{1}=$ Aplikasi mulsa

Tabel 2. Hasil pengamatan pengaruh sistem olah tanah dan aplikasi mulsa terhadap variabel tanah erosi hasil transformasi $2 x($ (" $x+0,5)$

\begin{tabular}{ccccccccc}
\hline \multirow{2}{*}{ Perlakuan } & \multicolumn{9}{c}{ Ulangan } & \multirow{2}{*}{ Jumlah } & \multirow{2}{*}{ Rata-Rata } & Standar Deviasi \\
\cline { 2 - 5 } & 1 & 2 & 3 & 4 & & & \multirow{2}{*}{0.38} \\
$\mathrm{~T}_{1} \mathrm{M}_{0}$ & 2,82 & 2,1 & 2,1 & 2,7 & 9,73 & 2,43 & 0.38 \\
$\mathrm{~T}_{0} \mathrm{M}_{0}$ & 2,23 & 1,98 & 1,98 & 2,79 & 8,98 & 2,25 & 0.47 \\
$\mathrm{~T}_{1} \mathrm{M}_{1}$ & 3,18 & 2,73 & 2,73 & 2,03 & 10,66 & 2,67 & 0.41 \\
$\mathrm{~T}_{0} \mathrm{M}_{1}$ & 2,02 & 2,01 & 2,01 & 2,84 & 8,89 & 2,22 & 1.65 \\
\hline Total & 10,25 & 8,83 & 8,83 & 10,36 & 27,9 & 9,56 & \\
\hline Rata-rata & 2,56 & 2,21 & 2,21 & 2,59 & & & \\
\hline
\end{tabular}

Keterangan $: \mathrm{T}_{0}=$ Olah Tanah Minimum; $\mathrm{T}_{1}=$ Olah Tanah Intensif; $\mathrm{M}_{0}=$ Tanpa mulsa; $\mathrm{M}_{1}=$ Aplikasi mulsa 
lebih berpotensi menyebabkan erosi disbanding hujan dengan curah hujan yang sama namun dalam waktu yang lama. Intensitas curah hujan lebih menentukan aliran permukaan yang menimbulkan erosi. Menurut Banuwa (2013) aliran permukaan bertanggung jawab sebagai penyebab erosi, karena aliran permukaan ini akan mengangkut tanah dan bagian bagian tanah dari suatu tempat yang lebih tinggi ke tempat yang rendah.

Hubungan antara curah hujan dan erosi jika meningkatnya curah hujan maka erosi akan semakin besar dan hal tersebut dikarenakan curah hujan merupakan faktor iklim yang paling berpengaruh terhadap erosi yang terjadi. Menurut Arsyad (2010) bahwa besarnya curah hujan, intensitas dan distribusi hujan menentukan kekuatan dispersi hujan terhadap tanah, jumlah dan kecepatan aliran permukaan serta erosi. Curah hujan dalam suatu waktu mungkin tidak menyebabkan erosi apabila intensitas hujan rendah, dan hujan dengan intensitas hujan tinggi namun dalam waktu yang singkat.

Curah hujan merupakan faktor yang paling penting di daerah tropika sebagai agensi yang mampu merusak tanah melalui proses erosi. Proses erosi yang disebabkan oleh curah hujan ditentukan oleh jumlah, intensitas, durasi, ukuran butiran hujan dan kecepatan jatuhnya. Proses erosi dapat menurunkan produktivitas lahan yang ditunjukkan oleh menurunnya hasil pertanian (Okoba dan Sterk, 2006 dalam Wahyuningtyas, 2010). Erosi merupakan proses yang kompleks dimana salah satunya ditentukan oleh curah hujan. Curah hujan mempengaruhi terhadap jumlah dan kecepatan aliran permukaan tanah. Hal tersebut juga dipengaruhi oleh kemiringan lahan, kondisi pengolahan tanah dan vegetasi tanaman penutup tanah (Rahim, 2000 dalam Wahyuningtyas, 2010)

Perlakuan sistem pengolahan tanah tidak berbeda nyata mempengaruhi produksi tanaman kacang hijau. Karena produksi kacang hijau lebih dipengaruhi oleh tehnik budidaya dan pemupukan. Pengolahan tanah (full tillage) lebih dibutuhkan tanaman yang menghasilkan umbi. Pada tanaman kacang hijau tidak memerlukan pengolahan tanah secara intensif. Karena kacang hijau tidak menghasilkan umbi tetapi menghasilkan biji. Sehingga pada tanaman kacang hijau

Tabel 3. Hasil pengamatan pengaruh sistem olah tanah dan aplikasi mulsa terhadap variabel produksi kacang hijau

\begin{tabular}{|c|c|c|c|c|c|c|c|}
\hline \multirow{2}{*}{ Perlakuan } & \multicolumn{4}{|c|}{ Ulangan } & \multirow{2}{*}{ Jumlah } & \multirow{2}{*}{ Rata-Rata } & \multirow{2}{*}{ Standar Devias } \\
\hline & 1 & 2 & 3 & 4 & & & \\
\hline & \multicolumn{7}{|c|}{. $\mathrm{kg}$ ha- $1 /$ musim tanam....... } \\
\hline $\mathrm{T}_{1} \mathrm{M}_{0}$ & 0,84 & 0,75 & 0,33 & 0,89 & 2,81 & 0,7 & 0,26 \\
\hline $\mathrm{T}_{0} \mathrm{M}_{0}$ & 0,75 & 0,89 & 0,14 & 0,19 & 1,97 & 0,49 & 0,38 \\
\hline $\mathrm{T}_{1} \mathrm{M}_{1}$ & 1,03 & 0,84 & 0,56 & 0,66 & 3,09 & 0,77 & 0,21 \\
\hline $\mathrm{T}_{0} \mathrm{M}_{1}$ & 1,22 & 0,89 & 0,19 & 0,28 & 2,58 & 0,64 & 0,49 \\
\hline Total & 3,84 & 3,38 & 1,22 & 2,02 & 8,44 & 2,61 & 1,34 \\
\hline Rata-rata & 0,96 & 0,84 & 0,3 & 0,5 & & & \\
\hline
\end{tabular}

Keterangan : $\mathrm{T}_{0}=$ Olah Tanah Minimum; $\mathrm{T}_{1}=$ Olah Tanah Intensif; $\mathrm{M}_{0}=$ Tanpa mulsa; $\mathrm{M}_{1}=$ Aplikasi mulsa 
Tabel 4. Hasil pengamatan pengaruh sistem olah tanah dan aplikasi mulsa terhadap variabel gulma

\begin{tabular}{|c|c|c|c|c|c|c|c|}
\hline \multirow{2}{*}{ Perlakuan } & \multicolumn{4}{|c|}{ Ulangan } & \multirow{2}{*}{ Jumlah } & \multirow{2}{*}{ Rata-Rata } & \multirow{2}{*}{$\begin{array}{l}\text { Standar } \\
\text { Deviasi }\end{array}$} \\
\hline & 1 & 2 & 3 & 4 & & & \\
\hline & \multicolumn{7}{|c|}{........ton ha-1/ musim tanam............... } \\
\hline $\mathrm{T}_{1} \mathrm{M}_{0}$ & 11.88 & 18.13 & 9.38 & 5.69 & 45.06 & 11.27 & 5.23 \\
\hline $\mathrm{T}_{0} \mathrm{M}_{0}$ & 16.88 & 12.50 & 3.75 & 10.81 & 43.94 & 10.98 & 5.46 \\
\hline $\mathrm{T}_{1} \mathrm{M}_{1}$ & 15.00 & 9.69 & 6.88 & 2.56 & 34.13 & 8.53 & 5.21 \\
\hline $\mathrm{T}_{0} \mathrm{M}_{1}$ & 8.75 & 10.00 & 10.31 & 6.25 & 35.31 & 8.83 & 1.85 \\
\hline Total & 52.50 & 50.31 & 30.31 & 25.31 & 133.13 & 39.61 & 17.75 \\
\hline Rata-rata & 13.13 & 12.58 & 7.58 & 6.33 & & & \\
\hline
\end{tabular}

Keterangan : $\mathrm{T}_{0}=$ Olah Tanah Minimum; $\mathrm{T}_{1}=$ Olah Tanah Intensif; $\mathrm{M}_{0}=$ Tanpa mulsa; $\mathrm{M}_{1}=$ Aplikasi mulsa

cukup dengan pengolahan tanah minimum.

Perlakuan mulsa tidak berbeda nyata terhadap produksi kacang hijau. Hal ini sejalan dengan penelitian Raihana (2006) bahwa mulsa terlihat pengaruhnya, apabila kondisi lingkungan tumbuhmengalami cekaman kekeringan. Menurut (Santoso dkk., 1993 dalam Raihana, 2006) pemberian mulsa mampu meningkatkan hasil kacang hijau 30-40\% lebih tinggi dibandingkan tanpa mulsa. Hal ini diduga pada kondisi tanah saat penelitian berlangsung dalam keadaan yang tidak mengalami cekaman kekeringan dari awal pertumbuhan hingga akhir, karena selama penilitian masih terjadi hujan sehingga pemberian mulsa tidak terlihat pengaruhnya.

Hubungan erosi dan produksi tanaman kacang hijau yaitu jika erosi yang terjadi besar maka produksi tanaman akan menurun, hal ini karena erosi menyebabkan terkikisnya tanah bagian atas (top soil) sehingga unsur hara banyak yang terangkut terbawa erosi dan tanah yang terus menerus terjadi erosi maka unsur hara pada tanah tersebut semakin sedikit. Merurut Banuwa (2013), dampak erosi di tempat kejadian antara lain : menurunnya kesuburan tanah karena hilangnya lapisan tanah yang subur dan menurunnya produktivitas tanaman.

Perlakuan sistem pengolahan tanah tidak berbeda nyata mempengaruhi pertumbuhan gulma. Hal ini tidak sejalan dengan pendapat Juleha (2002) bahwa pengolahan tanah mampu menekan pertumbuhan gulma. Pada penelitian ini pengendalian gulma dilakukan hanya dua kali, saat pengolahan tanah dan pada saat pemberian mulsa. Gulma tidak dilakukan penyiangan hingga panen. Pemberian mulsa juga tidak berbeda nyata mempengaruhi pertumbuhan gulma.

Perlakuam sistem olah tanah (full tillage) tidak berbeda nyata mempengaruhi aliran permukaan, erosi, produksi kacang hijau dan bobot basah gulma., begitu juga dengan sistem olah tanah (minimum tillage). Hal ini menunjukkan perlakuan sistem olah tanah minimum mendapatkan hasil yang tidak berbeda atau sama dengan olah tanah full tillage. Sehingga untuk menanam kacang hijau dengan sistem olah tanah minimum tillage dapat menghemat waktu, biaya dan tenaga kerja dibandingkan dengan menggunakan pengolahan tanah full tillage. 


\section{KESIMPULAN}

Berdasarkan hasil penelitian, dapat disimpulkan bahwa (1) sistem olah tanah tidak menghasilkan aliran permukaan dan erosi yang berbeda pada pertanaman kacang hijau. (2) mulsa tidak dapat menekan aliran permukan dan erosi pada pertanaman kacang hijau dan (3) tidak ada interaksi yang terjadi antara perlakuan sistem olah tanah dan pemberian mulsa terhadap aliran permukaan, erosi, bobot gulma dan produksi tanaman kacang hijau.

\section{DAFTAR PUSTAKA}

Arsyad, Sitanala. 2010. Konservasi Tanah dan Air. Penerbit IPB (IPB Pers). Bogor.

Banuwa, I.S. 2013. Erosi. Kencana Prenada Media Group. Jakarta.

Gajri, P.R., V.K. Arora, and S.S. Prihar.2002. Tillage for Suistainable Cropping. The Haworth Press. New York

Gill, W.R., and G.E. Vanden Berg. 1967. Soil Dynamics in Tillage and Traction. USDA Agric. Handb. N. 316. U.S. Government Printing Office, Washington, DC.
Juleha, 2002. Penerapan Budiadaya Hasil Kedelai (Glycine max (L) Merr) denganTeknonologi Konvensional pada Beberapa Cara Pengendalian Gulma.Fakultas Pertanian. IPB.

Nurmi, O.Haridjaja, S.Arsyad, dan S Yahya. 2012. Infiltrasi Dan Aliran Permukaan Sebagai Respon Perlakuan Konservasi VegetatifPada Pertanaman Kakao. Jurnal Agro Teknologi Tropika, 1(1) : 1-8

Raihana, Y, dan E. William, 2006. Pemberian Mulsa Terhadap Tujuh Varietas Kacang Hijau dan Keharaan Tanah di Lahan Lebak Tengahan. Bul.Argon : 34(3) : 148-152

Suwarjo. 1981. Peranan Sisa-sisa Tanaman dalam Konservasi Tanah Tanah dan Air pada Usahatani Tanaman Semusin. Disertasi FPS IPB. Bogor

Utomo, M. 2012. Tanpa Olah Tanah: Teknologi Pengelolaan Pertanian Lahan Kering. Lembaga Penelitian Universitas Lampung. Bandar Lampung. 110 Halaman.

Wahyuningtyas, R. S. 2010. Melestarikan Tanah Dengan Olah Tanah Konservasi. Galam. 4: 81-96 